\title{
Influence of different shades and LED irradiance on the degree of conversion of composite resins
}

\section{Lívia Aguilera Gaglianone ${ }^{(a)}$ Adriano Fonseca Lima(a) Larissa Sgarbosa Napoleão de Araújo(a) \\ Andrea Nóbrega Cavalcanti(b) Giselle Maria Marchi ${ }^{(a)}$}

\footnotetext{
(a) Department of Restorative Dentistry, Operative Dentistry Area, Piracicaba Dental School, State University of Campinas, Piracicaba, SP, Brazil.

(b) Department of Oral Rehabilitation, School of Dentistry, School of Medicine and Public Health of Bahia, Salvador, BA, Brazil.
}

\begin{abstract}
The aim of this study was to evaluate the degree of conversion (DC) of two composite resins with different shades that were light cured by light-emitting diodes (LEDs) of different irradiances. Specimens $(5 \mathrm{~mm} \times 2 \mathrm{~mm}$ ) were prepared with a nanofilled (Filtek Supreme - A2E, A2D, and WE) or microhybrid resin (Opallis - A2E, A2D, and EBleach Low) and were randomly divided into 12 groups ( $\mathrm{n}=5 \mathrm{each}$ ) according to the composite resin and light-curing unit (Elipar FreeLight 2, $1250 \mathrm{~mW} /$ $\mathrm{cm}^{2}$; Ultralume $\left.5,850 \mathrm{~mW} / \mathrm{cm}^{2}\right)$. After $24 \mathrm{~h}$, the DC was measured on two surfaces (top and bottom) with Fourier Transform infrared spectroscopy (FTIR). Data were statistically analyzed with two-way ANOVA and Tukey test $(\alpha=0.05)$. Statistical differences among the surfaces were observed in all experimental conditions, with higher values on the top surface. The microhybrid resin presented the highest DCs for shades A2E and A2D on the top surface. The LED with higher irradiance promoted better DCs. Taken together, the data indicate that the shade of a composite resin and the irradiance of the light source affect the monomeric conversion of the restorative material.
\end{abstract}

Descriptors: Composite Resins; Polymerization; Curing Lights, Dental.

\section{Introduction}

To promote an adequate and natural appearance, composite resins are available in a variety of colors and shades; however, this characteristic can make the restorative procedure challenging for clinicians. ${ }^{1} \mathrm{Com}-$ posite resin shades vary substantially among manufacturers. ${ }^{2}$ Despite having the same designation (e.g., A2 or B1), characteristics like color and translucency can differ according to the composite type, because the composition and inorganic content influence the optical properties of these materials. ${ }^{3}$

As light passes through a translucent material, it is dispersed, such that an object cannot be viewed clearly through the material. In other words, translucency is an intermediate state between complete opacity and transparency. Composite resins with different translucencies can present distinct behaviors with regards to the degree of conversion (DC), due to light dispersion in the materials.

Different light sources can be used to stimulate photoinitiators to begin free radical formation and start the curing process. ${ }^{4-6}$ Efficient curing depends on the light-curing irradiance and wavelength emitted, ${ }^{7,8}$ such 
that the spectrum irradiated by the device is higher than the absorption spectrum of the photoinitiator. ${ }^{9}$ Despite having different levels of irradiance than halogen lamps (QTH), light-emitting diodes (LEDs) present irradiance concentrated around $470 \mathrm{~nm}$, coincident with the absorption peak of camphorquinone. ${ }^{8,10}$ In some situations, this characteristic favors the improved DC of dental adhesives. ${ }^{11}$ However, the influence of different irradiances on the DC of composite resins is questionable.

As manufacturers introduce more options for composite resins, with different shades and compositions to promote better performance and characteristics similar to those of the natural tooth, studies are necessary to evaluate the influence of these parameters on composite behavior.

The aim of this study was to evaluate the DC of composite resins (microhybrid and nanofilled) of different shades that were light cured by LEDs with distinct irradiances. The null hypothesis was that differences in DC would not be observed among the shades and types of composite resins, and that monomer conversion would not be influenced by the LEDs tested.

\section{Methodology}

Two composite resins were used in the current study:

- a nanofilled resin (Filtek Supreme XT) and

- a microhybrid resin (Opallis).

The commercial names, composition, and manufacturers of the resins used are listed in Table 1.

Specimens were divided into groups ( $\mathrm{n}=5$ each) according to the light-curing irradiance (EliparTM Freelight 2 [EF], 3M ESPE, St. Paul, USA, 1250 mW/ $\mathrm{cm}^{2}$; Ultralume 5 [UL], Ultradent Products Inc., South Jordan, USA, $\left.850 \mathrm{~mW} / \mathrm{cm}^{2}\right)$ and shades $(\mathrm{Su}-$ preme - A2E, A2D, and WE; Opallis - A2E, A2D, and EBleach Low). The experimental groups are listed in Table 2. The wavelength spectra and peak emissions of tested LEDs are presented in Figure 1.

Specimens were prepared with a metallic matrix ( $5 \mathrm{~mm} \varnothing$ and $2 \mathrm{~mm}$ height). Composite resin was inserted in a single increment. A mylar strip and $500 \mathrm{~g}$ weight were placed over the mold and left for $20 \mathrm{~s}$, to allow for better accommodation of the composite. Specimens were light cured according to the manufacturers' instructions (20 s with Filtek Supreme A2E/A2D/WE and Opallis A2E/ EBleach Low; or $40 \mathrm{~s}$ with Opallis A2D) with the light-curing unit corresponding to each group. Specimens were stored for $24 \mathrm{~h}$ at $37{ }^{\circ} \mathrm{C}$ under light-protected and dry

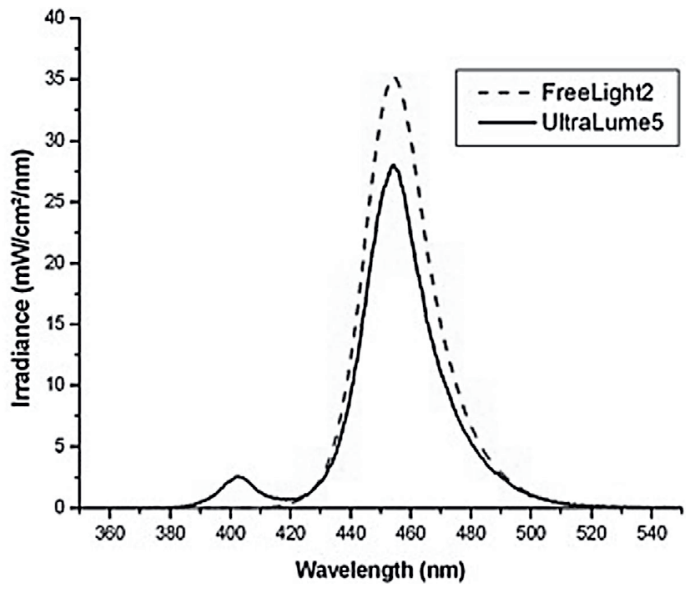

Figure 1 - Light spectrum profiles emitted by the light-curing units. Elipar Freelight 2 presented an emission spectrum between 415 and $520 \mathrm{~nm}$. Ultralume 5 presented a spectrum similar to that of Elipar Freelight 2; however, its wavelength spectrum was extended, with initiation at $385 \mathrm{~nm}$ and a peak at $405 \mathrm{~nm}$. Both light-curing units had a peak at $454 \mathrm{~nm}$.

Table 1 - Composition of the composite resins used in the present study.

\begin{tabular}{c|c|c}
\hline Composite & Composition & Manufacturer \\
\hline $\begin{array}{c}\text { Filtek } \\
\text { Supreme XT }\end{array}$ & $\begin{array}{c}\text { Bis-GMA, Bis-EMA, UDMA, TEGDMA } \\
\text { Filler: } 59.5 \% \text { by Wt - silane treated ceramic (65-75\% by Wt) } \\
\text { and silane treated sílica }(5-15 \% \text { by } W+\text { - size: } 20 \text { and } 75 \mathrm{~nm}\end{array}$ & $\begin{array}{c}3 \mathrm{M} \text { ESPE, } \\
\text { St. Paul, Min., USA }\end{array}$ \\
\hline Opallis & $\begin{array}{c}\text { Bis-GMA, Bis-EMA,TEGDMA } \\
\text { Filler: } 57 \% \text { by Wt - silane treated ceramic }(65-75 \% \text { by Wt) } \\
\text { and silane treated silica }(5-10 \% \text { by Wt) - size: } 3 \mu \mathrm{m}\end{array}$ & $\begin{array}{c}\text { FGM Produtos } \\
\text { Odontológicos Ltda, } \\
\text { Joinville, SC, Brazil }\end{array}$ \\
\hline
\end{tabular}

Bis-GMA (Bisphenol A Diglycidyl Ether Methacrylate), Bis-EMA (Bisphenol A Polyethylene Glycol Diether Dimethacrylate), TEGDMA (Triethylene Glycol Dimethacrylate), UDMA (Diurethane Dimethacrylate). 
conditions. After this period, both the top and bottom surfaces were polished with abrasive papers of decreasing grit (400, 600, and 1200, Buehler Ltd., Lake Bluff, USA) to analyze monomer conversion.

The DC of the composite resin was measured on the bottom and top surfaces of each specimen. Measurements were performed with Fourier Transform infrared spectroscopy (FTIR - Spectrum 100

Table 2 - Experimental groups according to the light-curing unit, type, and shade of composite resin.

\begin{tabular}{c|c|c}
\hline Composite resin & Light curing unit & Shades \\
\hline \multirow{4}{*}{ Micro-hybrid } & \multirow{3}{*}{ EF } & A2E \\
\cline { 3 - 3 } & & A2D \\
\hline \multirow{2}{*}{ Micro-hybrid } & \multirow{2}{*}{ UL } & EBleach Low \\
\cline { 3 - 3 } & & A2E \\
\hline \multirow{3}{*}{ Nanofilled } & \multirow{3}{*}{ EF } & A2D \\
\cline { 3 - 3 } & & EBleach Low \\
\hline \multirow{2}{*}{ Nanofilled } & \multirow{2}{*}{ UL } & A2E \\
\hline & & A2D \\
\hline & & A2E \\
\hline
\end{tabular}

Optica; PerkinElmer, USA), equipped with an attenuated total reflectance (ATR) device, in a room with controlled temperature and humidity. The DC (\%) was evaluated in the absorbance mode with a baseline technique ${ }^{12}$ and was traced by the Spectrum program (Spectrum 100 Optica; PerkinElmer, USA). The DC was calculated with an equation considering the intensity of the $\mathrm{C}=\mathrm{C}$ stretching vibration (peak height) at $1638 \mathrm{~cm}^{-1}$ and, as an internal standard, with symmetric ring stretching at $1608 \mathrm{~cm}^{-1}$.

The DC results were statistically analyzed by split-plot two-way ANOVA and Tukey test $(\alpha=0.05)$ with the SAS 9.1 software package (SAS Institute, Cary, USA).

\section{Results}

Table 3 shows the results obtained in the present study. A significant interaction was found between the variables "composite resin" and "light source" $(p<0.01)$. Specimen tops showed better DC values than specimen bottoms. The nanofilled composite resin presented lower DC values than the microhybrid resin in all situations, except for the A2E shade (bottom), which presented similar results. The highirradiance LED (Elipar) showed better DC values than the third-generation LED (Ultralume 5).

Table 3 - Percent means (standard deviations) of the degree of conversion, according to the lightcuring unit, type, and shade of the composite resin and surface evaluated.

\begin{tabular}{|c|c|c|c|c|}
\hline \multirow{2}{*}{ Light curing unit } & \multirow{2}{*}{ Composite resin and shades } & \multicolumn{2}{|c|}{ Surface } & \\
\hline & & Top & Bottom & \\
\hline \multirow{6}{*}{ EF } & Micro-hybrid EBleach Low & $59.3(3.7) \mathrm{Ba}$ & $52.2(3.6) \mathrm{Ab}$ & \\
\hline & Micro-hybrid A2D & 63.5 (1.4) ABa & $54.0(2.0) \mathrm{Ab}$ & \\
\hline & Micro-hybrid A2E & $66.3(10.3) \mathrm{Aa}$ & 55.4 (3.7) Ab & $@$ \\
\hline & Nanofilled WE & $53.2(2.8) \mathrm{Ca}$ & 47.9 (2.3) Bb & \\
\hline & Nanofilled A2D & $53.3(4.7) \mathrm{Ca}$ & $37.7(1.3) \mathrm{Cb}$ & \\
\hline & Nanofilled A2E & $55.9(1.3) \mathrm{Ca}$ & 49.3 (3.8) ABb & \\
\hline \multirow{6}{*}{ UL } & Micro-hybrid EBleach Low & $57.7(1.6) \mathrm{Ba}$ & $55.4(2.4) \mathrm{Ab}$ & \\
\hline & Micro-hybrid A2D & $62.9(2.5) \mathrm{ABa}$ & $51.5(2.1) \mathrm{Ab}$ & \\
\hline & Micro-hybrid A2E & 64.7 (1.1) Aa & $54.4(0.9) \mathrm{Ab}$ & * \\
\hline & Nanofilled WE & 49.7 (5.9) Ca & $44.9(5.1) \mathrm{Bb}$ & \\
\hline & Nanofilled A2D & $51.5(8.1) \mathrm{Ca}$ & $31.8(2.7) \mathrm{Cb}$ & \\
\hline & Nanofilled A2E & $55.5(1.8) \mathrm{Ca}$ & 47.9 (3.1) $\mathrm{ABb}$ & \\
\hline
\end{tabular}

Different letters indicate statistically significant difference (two-way ANOVA/Tukey's Test, $p<0.05$ ). Upperand lower-case letters compare resin on columns and surfaces on lines, respectively.*/@ indicate differences among the light-curing units. 


\section{Discussion}

According to the current results, the resin shade and LED irradiance can affect the DC of the composite resin. Therefore, the null hypothesis of this study must be rejected.

The specimen bottoms (2 $\mathrm{mm}$ height) presented lower DC values than the tops. This result can be explained by the increased distance between the light-curing tip and bottom of the composite, which attenuates light activation at the bottom surface and compromises the extent of curing. ${ }^{13,14}$ Similarly, Beun et al. ${ }^{15}$ showed a progressive reduction in DC depending on the specimen thickness when either QTH or LED was used.

The microhybrid resin promoted better conversion than the nanofilled resin. According to some studies, the DC is influenced by the organic content, because characteristics such as reactivity and monomer mobility are related to the formation of polymeric chains. ${ }^{16,17}$ The higher amount of filler present in the nanofilled resin could influence the results by promoting a lower DC.

Nanofilled composites are characterized by the wide distribution of nanosized filler particles. This characteristic improves the mechanical properties of the resin. Nevertheless, due to the higher amount of filler, a reduction in the organic matrix can be observed in the interfacial region between the particles. This reduction alters the DC, which is directly related to the concentration of monomer content. ${ }^{18}$ In addition, a reduced light intensity reaches the photoinitiator, due to the proximity of the fillers. As a result, the formation of free radicals (which are responsible for the curing process) is reduced.

No differences were observed among the nanofiller resins in terms of the shades on the top surfaces. However, EBleach Low (which was developed to restore bleached teeth) showed lower DC values with the microhybrid resins. It can be speculated that EBleach Low presents an alternative photoinitiator, because camphorquinone has a yellow coloration. ${ }^{19}$ Alternative initiators are activated at different wavelengths that are not provided by the LEDs used, due to the short spectrum of light that they emit, which compromises the curing efficacy of this material. ${ }^{20}$ Because manufacturers are usually reluc- tant to reveal the exact compositions of their products, ${ }^{21}$ it is not possible to determine whether this situation explains the current results completely.

Greater DC values and similar results were observed among the microhybrid resins on the specimen bottoms. However, the nanofilled resin A2D showed a reduced DC compared to the other shades. As described above, use of high amounts of filler can reduce the formation of free radicals and compromise the DC. ${ }^{18}$ The high amount of filler and reduced translucency of this resin likely interfered with the passage of light through the material and decreased the monomeric conversion. This problem was not observed with the microhybrid resin, probably because of the extended curing time applied to shade A2D. The manufacturer's instructions were followed rigidly, because manufacturers generally recommend the best way to use their materials to obtain optimal results. Nevertheless, use of the extended curing time could have promoted improved monomer conversion of the tested nanofilled resins.

Use of high-irradiance LED $\left(1250 \mathrm{~mW} / \mathrm{cm}^{2}\right)$ resulted in the best DC values. Despite having narrow wavelength spectra (between 415 and $520 \mathrm{~nm}$ ), the LEDs tested presented a peak emission of around $454 \mathrm{~nm}$ (Figure 1). This peak emission is near the absorption peak of camphorquinone $(470 \mathrm{~nm})$, which was the photoinitiator used in the resins evaluated. Because the two LEDs displayed similar wavelength spectra, the high irradiance of Elipar FreeLight was most likely responsible for the obtained results. The third-generation LED used (Ultralume 5) has auxiliary LEDs, which expanded the emitted wavelength spectrum $^{22}$ (Figure 1). However, due to the proximity of the light source to the specimen at the moment of curing, the advantage of the auxiliary LEDs was not fully realized. As a result, the optimal performance of this LED was restricted.

In conclusion, not only the light source, but also the intrinsic properties of the resin (e.g., translucency, amount, type and size of filler), influence material polymerization. To obtain the best DC, when using resins with low translucency, an increase in curing time (mainly at the bottom of the increment) should be considered. 


\section{Conclusion}

The DC of composite resin is influenced by the light source, with high-irradiance LEDs promoting better DC values. Specimen bottoms presented lower DC values in all situations tested, and the nanofilled resin presented lower means of DC. The shade can influence the DC of the top of microhybrid resins and the bottom of nanofilled resins.

\section{References}

1. Kim BJ, Lee YK. Influence of the shade designation on the color difference between the same shade-designated resin composites by the brand. Dent Mater. 2009 Sep;25(9):1148-54.

2. Swift EJ Jr, Hammel SA, Lund PS. Colorimetric evaluation of vita shade resin composites. Int J Prosthodont. 1994 JulAug;7(4):356-61.

3. Lee YK, Lim BS, Rhee SH, Yang HC, Powers JM. Color and translucency of A2 shade resin composites after curing, polishing and thermocycling. Oper Dent. 2005 JulAug;30(4):436-42.

4. Ogunyinka A, Palin WM, Shortall AC, Marquis PM. Photoinitiation chemistry affects light transmission and degree of conversion of curing experimental dental resin composites. Dent Mater. 2007 Jul;23(7):807-13.

5. da Silva EM, Poskus LT, Guimaraes JG. Influence of lightpolymerization modes on the degree of conversion and mechanical properties of resin composites: a comparative analysis between a hybrid and a nanofilled composite. Oper Dent. 2008 May-Jun;33(3):287-93.

6. da Silva EM, Poskus LT, Guimaraes JG, de Araujo Lima Barcellos A, Fellows CE. Influence of light polymerization modes on degree of conversion and crosslink density of dental composites. J Mater Sci Mater Med. 2008 Mar;19(3):1027-32.

7. Jimenez-Planas A, Martin J, Abalos C, Llamas R. Developments in polymerization lamps. Quintessence Int. 2008 Feb;39(2):e74-84.

8. Leonard DL, Charlton DG, Roberts HW, Cohen ME. Polymerization efficiency of LED curing lights. J Esthet Restor Dent. 2002;14(5):286-95.

9. Chen YC, Ferracane JL, Prahl SA. Quantum yield of conversion of the photoinitiator camphorquinone. Dent Mater. 2007 Jun;23(6):655-64.

10. Uhl A, Sigusch BW, Jandt KD. Second generation LEDs for the polymerization of oral biomaterials. Dent Mater. 2004 Jan;20(1):80-7.

11. Faria-e-Silva AL, Lima AF, Moraes RR, Piva E, Martins LR. Degree of Conversion of Etch-and-Rinse and Self-etch Adhesives Light-cured Using QTH or LED. Oper Dent. 2010 Nov-Dec;35(6):649-54.

\section{Acknowledgements}

This research was partially supported by the Fundação de Amparo à Pesquisa do Estado de São Paulo (Grants: \#2007/02800-3; \#2009/08992-7; \#2009/03763-0 and \#2009/03661-2) and Conselho Nacional de Pesquisa e Desenvolvimento - PQ/ CNPq (Grant: \#304076/2009-0).

12. Rueggeberg FA, Hashinger DT, Fairhurst CW. Calibration of FTIR conversion analysis of contemporary dental resin composites. Dent Mater. 1990 Oct;6(4):241-9.

13. Jandt KD, Mills RW, Blackwell GB, Ashworth SH. Depth of cure and compressive strength of dental composites cured with blue light emitting diodes (LEDs). Dent Mater. 2000 Jan;16(1):41-7.

14. Froes-Salgado NR, Pfeifer CS, Francci CE, Kawano Y. Influence of photoactivation protocol and light guide distance on conversion and microleakage of composite restorations. Oper Dent. 2009 Jul-Aug;34(4):408-14.

15. Beun S, Glorieux T, Devaux J, Vreven J, Leloup G. Characterization of nanofilled compared to universal and microfilled composites. Dent Mater. 2007 Jan;23(1):51-9.

16. Sideridou I, Tserki V, Papanastasiou G. Effect of chemical structure on degree of conversion in light-cured dimethacrylate-based dental resins. Biomaterials. 2002 Apr;23(8):181929.

17. Lovell LG, Newman SM, Bowman CN. The effects of light intensity, temperature, and comonomer composition on the polymerization behavior of dimethacrylate dental resins. J Dent Res. 1999 Aug;78(8):1469-76.

18. Turssi CP, Ferracane JL, Vogel K. Filler features and their effects on wear and degree of conversion of particulate dental resin composites. Biomaterials. 2005 Aug;26(24):4932-7.

19. Shin DH, Rawls HR. Degree of conversion and color stability of the light curing resin with new photoinitiator systems. Dent Mater. 2009 Aug;25(8):1030-8.

20. Arikawa H, Takahashi H, Kanie T, Ban S. Effect of various visible light photoinitiators on the polymerization and color of light-activated resins. Dent Mater J. 2009 Jul;28(4):454-60.

21. Van Landuyt KL, Snauwaert J, De Munck J, Peumans M, Yoshida Y, Poitevin A, et al. Systematic review of the chemical composition of contemporary dental adhesives. Biomaterials. 2007 Sep;28(26):3757-85.

22. Brandt WC, Schneider LF, Frollini E, Correr-Sobrinho L, Sinhoreti MA. Effect of different photo-initiators and light curing units on degree of conversion of composites. Braz Oral Res. 2010 Jul-Sep;24(3):263-70. 